\title{
Introduction
}

\section{Acquired dyslexia and dysgraphia across scripts}

\author{
Brendan Stuart Weekes \\ Laboratory of Communication Science, University of Hong Kong, Hong Kong, China \\ Tel.: +852 2241 5986; Fax: +852 2241 5988; E-mail: weekes@hku.hk
}

Keywords: Models of reading, Spelling, Biscript reading, Bilingualism

Many studies have investigated the cognitive processes used to read and to spell in English. Much of our kowledge about these processes comes from reports of patients with acquired dyslexia and dysgraphia, first identified in the behavioral neurology clinic. As in all clinical studies, the detail in these reports includes description of preserved and impaired abilities of the patient, usually with reference to a cognitive neuropsychological model of reading and spelling $[6,12,13,26$, $28,29]$. The beauty of these reports is the insight provided to the clinician and to theorist about the topography of cognitive processing, allowing science to "carve nature at its joints'.

One criticism of this research is the emphasis on European languages. However, a review of acquired dyslexia and dysgraphia in languages other than English reveals an interesting fact. Many cases are reported in Behavioral Neurology - a revelation that reflects the global reach and sophistication of this readership. It is therefore a great privilege to present this Special Issue on the topic of Reading and Writing Disorders Across Scripts.

The question posed to the authors (and readers) of the papers in this Special Issue is whether the processes identified for reading and spelling in cognitive neuropsychological models developed for English, extend to other languages. This is not a trivial question that is limited to the armchair. Language processing in bilingual speakers is moving towards the front of cognitive neuropsychological enquiry simply because bilingual speakers are the majority of speakers in many language environments. Thus, it is of interest to know about dyslexia and dysgraphia in Chinese, Korean and Urdu for theoretical reasons but also because it is necessary to know if the cognitive processes used to read and to spell in one language have any effects on reading and spelling in another language [see 8, 9, 16 for interesting answers]. If the cognitive mechanisms used to read and to spell in one language impact on reading and spelling in another language then several clinical implications follow, specifically for the treatment of acquired dyslexia and dysgraphia in bilingual speakers $[23,26$, 40].

The contributors to this Special Issue report on patterns of acquired dyslexia and dysgraphia in Arabic, Chinese, Greek, Hebrew, Hungarian, Italian, Japanese, Russian, Slovak and Spanish. One unique feature is reports of multilingual speakers with reading and spelling disorders in different languages (Druks et al.; Friedmann and Haddad; Kambanaros et al.; Senaha and Parente). These cases not only highlight the striking similarities in the patterns of dyslexia and dysgraphia across languages, they converge on the view that cognitive processes used to read and to spell are independent of linguistic differences. Such reports have implications for theoretical models of bilingual language processing because they suggest language 'non-selective' access to the reading system. For example, the Bilingual Interac- 
tive Activation (BIA) model developed by Dijkstra and colleagues [8,9] assumes an integrated system for oral reading across languages with language non-selective access to the oral reading system [see also 28, 29].

Wilson, Kahlaoui and Weekes [40] reviewed extant reports of acquired disorders of reading and spelling in bilingual speakers. Their review found that the error patterns of surface, phonological and deep dyslexia in monolingual speakers in different languages are observed in bilingual speakers $[1,2,11,14,15,19,20,24$, 30,39]. That is not to say that all cases of acquired dyslexia in bilingual speakers show the same pattern of oral reading impairment in both languages. Weekes et al. [38] report Mongolian-Chinese bilingual speakers with different reading errors in two types of script. The Mongolian language has an alphabetic script with a set of sublexical mappings from orthography to phonology. Weekes et al. observed semantic oral reading errors in Mongolian but semantically-related translation errors in Chinese i.e. reading a Chinese character using a semantically-related Mongolian syllable. One patient produced within-language semantic oral reading errors in Mongolian e.g. table read as "stool", but did not produce these errors in Chinese. Language selective reading errors are a challenge for the BIA+ model.

Language selective reading errors are observed in other bilingual speakers. Laine et al. [36] reported a Swedish-Finnish speaker who had acquired dyslexia in both alphabetic scripts but was more likely to make phonological errors when reading Swedish than Finnish. García-Caballero et al. [25] reported a Galician-Spanish patient who had reading difficulties only for Galician - a transparent orthography that shares morphology and vocabulary with Portuguese. Raman and Weekes [30] reported a TurkishEnglish speaker who was surface dyslexic in English but deep dysgraphic in Turkish. Such reports suggest that oral reading problems manifest themselves differently across languages, according to the unique properties of a script.

It is of interest that language selective oral reading errors are not limited to bilingual speakers. The most striking cases are reports of selective reading impairments in biscriptal patients showing that the type of script used within a language can have an impact on acquired dyslexia. Korean uses two different scripts: an ideographic writing system Hanja and syllabic writing system Hangul. Disorders of reading and writing for ideographic and syllabic characters in Korean can be script specific [18]. These reports are difficult to reconcile with non-selective models of bilingual oral reading [8]. Indeed, Caramelli et al. [4] observed a within language dissociation in reading errors across script in a Brazilian Portuguese-Japanese (Nisei) bilingual speaker who produced more oral reading errors in Japanese (ideographic) than Portuguese (alphabetic) even though he acquired both languages at an early age. Of even more interest was the differential pattern of reading impairment within the Japanese language for Kanji and Kana script. Japanese script uses an ideographic writing system (Kanji) adopted from Chinese characters and a syllabic system (Kana). Reports of monolingual Japanese speakers with acquired dyslexia who read well in one script and not the other i.e. biscriptal dyslexia are plentiful [7,32-34]. However, Caramelli's report was the first to show that acquired dyslexia within Japanese transfers to irregularly spelled Portuguese words (see also Senaha and Parente, this volume).

A review of the cases reported with acquired dyslexia and dysgraphia in bilingual speakers is summarized in Table 1 (biscriptal cases are omitted). Each case is described in terms of the language status i.e. the first acquired (L1) and the second acquired (L2) language, the cerebral pathology (if reported), the pattern of reading impairment and the characterisation of acquired dyslexia stated in the case report. The summary shows a mixed pattern. For some cases there are no differences in quantity or quality of oral reading errors across languages, even if the languages use very different scripts (e.g., Arabic-Hebrew). However for the majority of cases there is some effect of language status on performance with different patterns of reading errors across languages. Two features that emerge from the summary are that 1) effects of language status do not necessarily favour the first acquired language and 2) effects of language status do not depend on similarity between scripts. For example, there are reports of Chinese-English speakers who produce more errors in Chinese (L1) than English (L2) but another report shows the opposite pattern. Reports of acquired dyslexia and dysgraphia in bilingual and biscript patients will continue to challenge and inform cognitive neuropsychological models of reading as will cases of reading and writing disorders in monolingual speakers such as those reported here by Crepaldi et al., Hricova et al., Mondini et al., Semenza et al., and Wilson et al.

In closing, I would very much like to thank Argye Hillis and Naama Friedmann for encouragement and help in editing this Special Issue. Thanks also to the contributors for their insights into acquired disorders of reading and writing across scripts. 


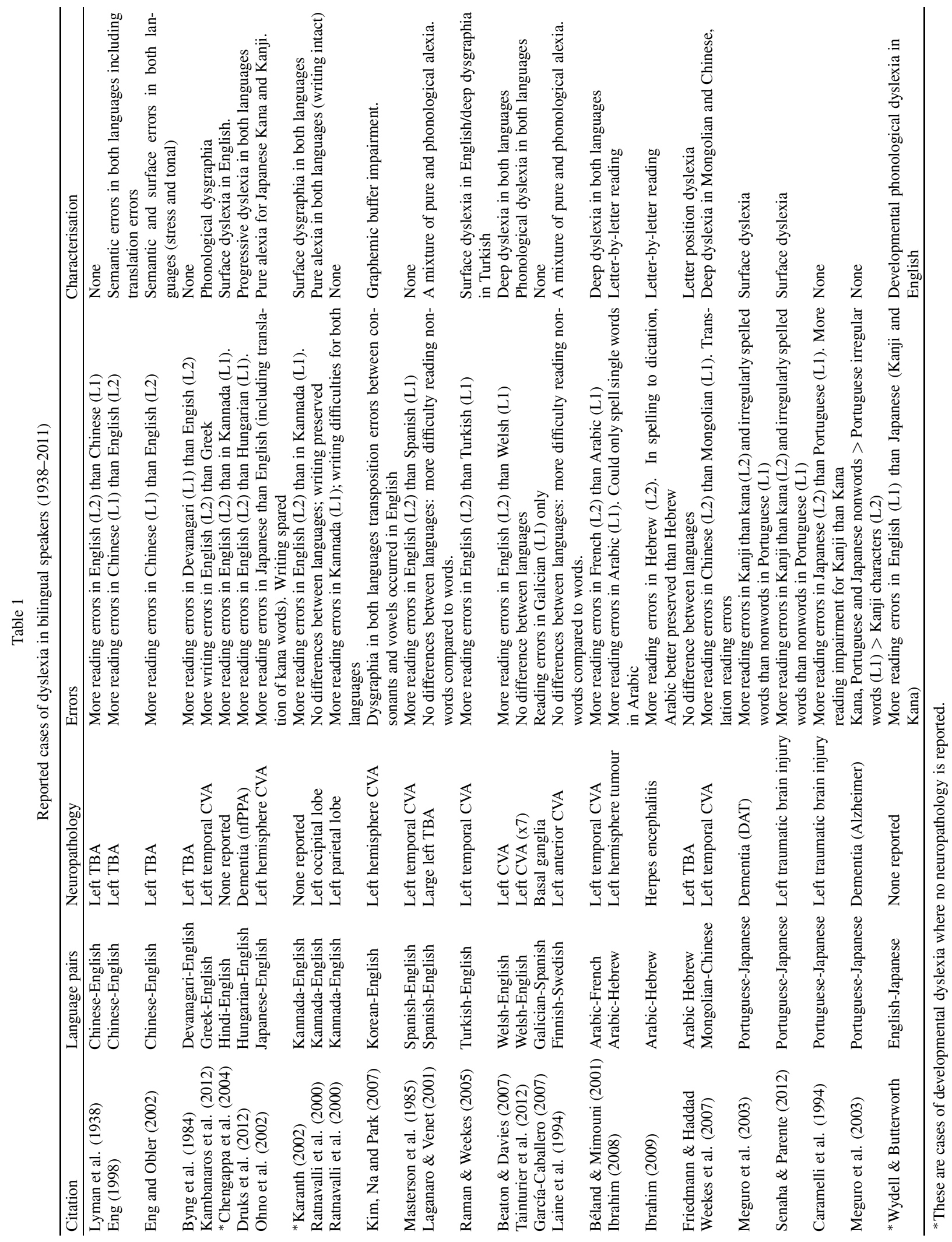




\section{References}

[1] A. Beaton and W. Davies, Semantic errors in deep dyslexia: Does orthographic depth matter? Cognitive Neuropsychology 24(3) (2007), 312-323

[2] R. Beland and Z. Mimouni, Deep dyslexia in the two languages of an Arabic/French bilingual patient, Cognition 82 (2001), 77-126.

[3] S. Byng, M. Coltheart, J. Masterson, M. Prior and J. Riddoch, Bilingual biscriptal deep dyslexia, The Quarterly Journal of Experimental Psychology Section A 36(3) (1984), 417-433.

[4] P. Caramelli, M. Parente, M.L. Hosogi, M. Bois and A.R. Lecours, Unexpected reading dissociation in a Brazilian Nisei with crossed aphasia, Behavioral Neurology 7 (1994), 156164.

[5] S. Chengappa, S. Bhat and P. Padakannaya, Reading and writing skills in multilingual multiliterate aphasics: Two case studies, Reading and Writing 17(1-2) (2004), 121-135.

[6] M. Coltheart, K. Rastle, C. Perry, R. Langdon and J. Ziegler, DRC: A dual route cascaded model of visual word recognition and reading aloud, Psychological Review 108 (1) (2001), 204 256.

[7] F. Cremaschi and E. Dujovny, Japanese language and brain localization, Neurological Research 18(3) (1996), 212-216.

[8] T. Dijkstra and W.J.B van Heuven, The architecture of the bilingual word recognition system: From identification to decision, Bilingualism: Language and Cognition 5 (2002), 175197.

[9] T. Dijkstra, M. Timmermans and H. Schriefers, On being blinded by your other language: Effects of task demands on interlingual homograph recognition, Journal of Memory and Language 42 (2000), 445-464.

[10] N. Eng and L.K. Obler, Acquired dyslexia in a biscript reader following traumatic brain injury: A second case, Topics in Language Disorders 22(5) (2002), 5-19.

[11] A. Garcia-Caballero, I. Garcia-Lado, J. Gonzalez-Hermida, R. Areu, M.J. Recimil, O. Juncos Rabadan, S. Lamas and F.J. Jorge, Paradoxical recovery in a bilingual patient with aphasia after right capsuloputaminal infarction, Journal of Neurology, Neurosurgery and Psychiatry 78 (2007), 89-91.

[12] A. Hillis and A. Caramazza, Converging evidence for the interaction of semantic and phonological information in accessing lexical information for spoken output, Cognitive Neuropsychology 12 (1995), 187-227.

[13] G. Houghton and M Zorzi, Normal and impaired spelling in a connectionist dual-route architecture, Cognitive Neuropsychology 20(2) (2003), 115-162.

[14] R. Ibrahim, Performance in L1 and L2 observed in ArabicHebrew bilingual aphasia following brain tumour: a case constitutes double dissociation, Psychology Research and $\mathrm{Be}$ haviour Management 11 (2008), 11-19.

[15] R. Ibrahim, Selective deficit of second language: a case study of a brain damaged Arabic-Hebrew bilingual patient, $B e$ havioural and Brain Functions 5 (2009), 1-10.

[16] D. Jared and J.F. Kroll, Do bilinguals activate phonological representations in one or both of their languages when naming words? Journal of Memory and Language 44 (2001), 2-31.

[17] P. Karanth, The search for deep dyslexia in syllabic writing systems, Journal of Neurolinguistics 15(2) (2002), 143-155.

[18] H. Kim, D.L. Na and E.S. Park, Intransigent vowel-consonant position in Korean dysgraphia: Evidence of spatial-con- structive representation, Behavioural Neurology 18 (2007), 91-97.

[19] M. Laine, J. Niemi, P. Koivuselkä-Sallinen, E. Ahlsén and J. Hyönä, A neurolinguistic analysis of morphological deficits in a Finnish-Swedish bilingual aphasic, Clinical Linguistics and Phonetics 8 (1994), 177-200.

[20] M. Laganaro and M. Overton-Venet, Acquired alexia in multilingual aphasia and computer-assisted treatment in both languages: issues of generalisation and transfer, Folia Phoniatrica et Logoaedica $\mathbf{5 3}$ (2001), 135-144.

[21] M. Laine, P. Neimi, J. Neimi and P. Koivuselkä-Sallinen, Semantic errors in deep dyslexia, Brain and Language 38 (1990), 207-214.

[22] M. Laine, J. Niemi, P. Koivuselkä-Sallinen, E. Ahlsén and J. Hyönä, A neurolinguistic analysis of morphological deficits in a Finnish-Swedish bilingual aphasic, Clinical Linguistics and Phonetics 8 (1994), 177-200.

[23] B. Lorenzen and L. Murray, Bilingual aphasia: a theoretical and clinical review, American Journal of Speech-Language Pathology 17 (2008), 299-317.

[24] J. Masterson, M. Coltheart and P. Meara, Surface dyslexia in a language without irregularly spelled words, in: Surface Dyslexia: Neuropsychological and Cognitive Studies of Phonological Reading, K. Patterson, J.C. Marshall and M. Coltheart, eds, Hove, UK: Lawrence Erlbaum, 1985, pp. 215223.

[25] M. Meguro, M.L.H. Senaha, P. Caramelli, J. Ishizaki, R.Y.S. Chubacci, H. Ambo, R. Nitrini and A. Yamadori, Language deterioration in four Japanese-Portuguese bilingual patients with Alzheimer's disease: a trans-cultural study of Japanese elderly immigrants in Brazil, Psychogeriatrics 3(2) (2003), 63-68.

[26] L.K. Obler, Dyslexia in bilinguals, in: Dyslexia: A Global Issue, R.N. Malatesha and H.A. Whitaker, eds, The Hague: Martineau and Nijhoff, 1983, pp. 477-496.

[27] T.K. Ohno, S. Takeda, S. Kato and S. Hirai, Pure alexia in a Japanese-English bilingual: dissociation between the two languages, Journal Neurological Science 249 (2002), 105107.

[28] D.C. Plaut, J.D. McClelland, M.S. Seidenberg and K. Patterson, Understanding normal and impaired word reading: Computational principles in quasi-regular domains, Psychological Review 103 (1996), 56-115.

[29] D.C. Plaut, Graded modality-specific specialization in semantics: A computational account of optic aphasia, Cognitive Neuropsychology 19(7) (2002), 603-639.

[30] I. Raman and B.S. Weekes, Acquired dyslexia and dysgraphia in a biscriptal Turkish-English Reader, Annals of Dyslexia 55(1) (2005), 71-96.

[31] E. Ratnavalli, G. Geetha Murthy, D. Nagarajaa, M. Veerendrakumara, M. Jayaramb and P.N. Jayakumarc, Alexia in Indian bilinguals, Journal of Neurolinguistics 13(1) (2000), 3746.

[32] Y. Sakurai, T. Momose, M. Iwata, Y. Sudo, K. Ohtomo and I. Kanazawa, Different cortical activity in reading of Kanji words, Kana words and Kana nonwords, Cognitive Brain Research 9 (2000), 111-115.

[33] Y. Sakurai, M. Asami and T. Mannen, Alexia and agraphia with lesions of the angular and supramarginal gyri: Evidence for the disruption of sequential processing, Journal of the Neurological Sciences 288(1-2) (2010), 25-33.

[34] M. Satoh, K. Takeda and S. Kuzuhara, Agraphia in intellectually normal Japanese patients with ALS: omission of Kana letters, Journal of Neurology 256 (2009), 1455-1460.

[35] M.L.H. Senaha and M.A.M.P. Parente, Acquired dyslexia in three writing systems: study of a Portuguese-Japanese bilingual aphasic patient, Behavioural Neurology, (in press). 
[36] M.J. Tainturier, J. Roberts, S. Schiemenz and E.C. Leek, Do reading processes differ in transparent vs. opaque orthographies? A study of acquired dyslexia in Welsh/English bilinguals, (in press).

[37] B.S. Weekes, Acquired disorders of reading and writing: Cross-script comparisons, Behavioural Neurology 16 (2005), 51-57.

[38] B.S. Weekes, I.F. Su, W.G. Yin and X.H. Zhang, Oral reading in bilingual aphasia: evidence from Mongolian and Chinese,
Bilingualism: Language and Cognition 10(2) (2007), 201210.

[39] B.S. Weekes and I. Raman, Bilingual deep dysphasia, Cognitive Neuropsychology 25(3) (2008), 411-436.

[40] M.A. Wilson, K. Kahlaoui and B.S. Weekes, Acquired dyslexia and dysgraphia in bilinguals across alphabetical and nonalphabetical scripts, in: Multilingual Aphasia, M. Gitterman and L. Obler, eds, Multilingual Matters, Clevendon, UK, 2012. 


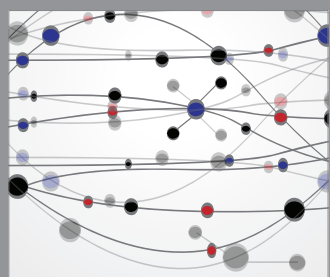

The Scientific World Journal
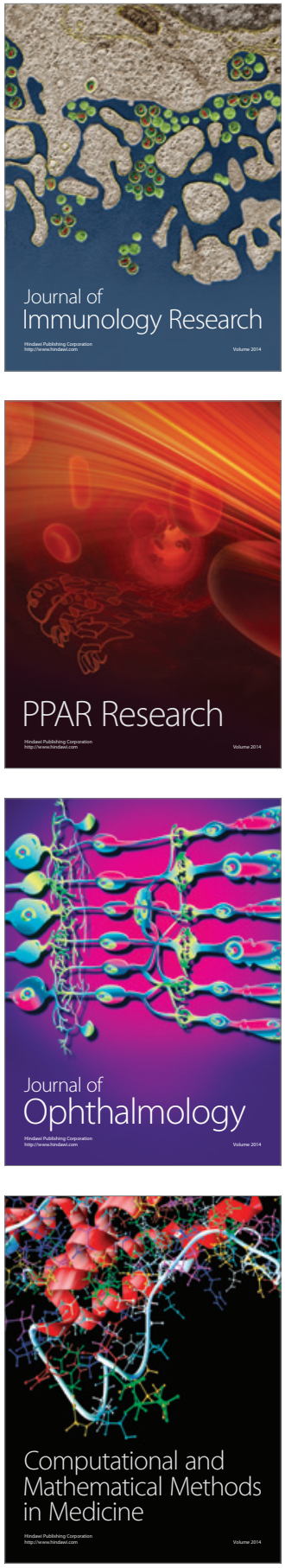

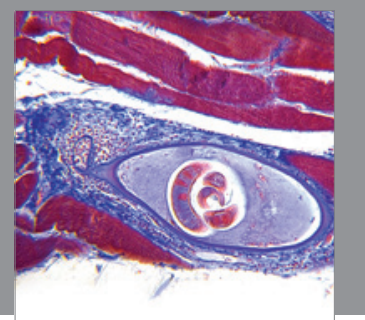

Gastroenterology

Research and Practice
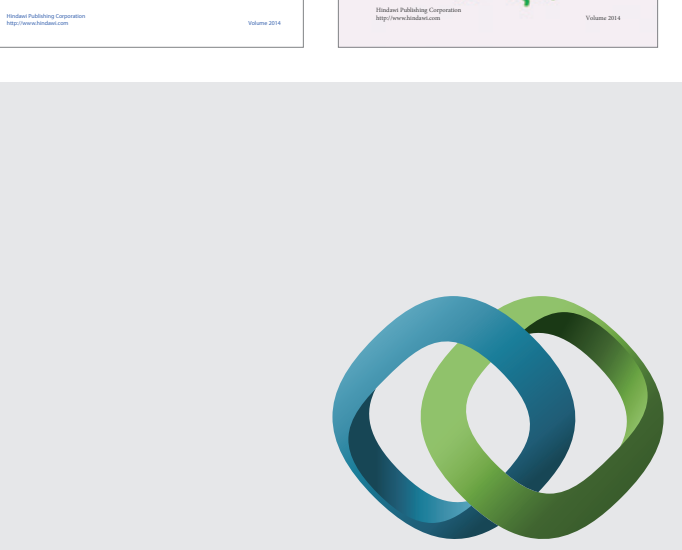

\section{Hindawi}

Submit your manuscripts at

http://www.hindawi.com
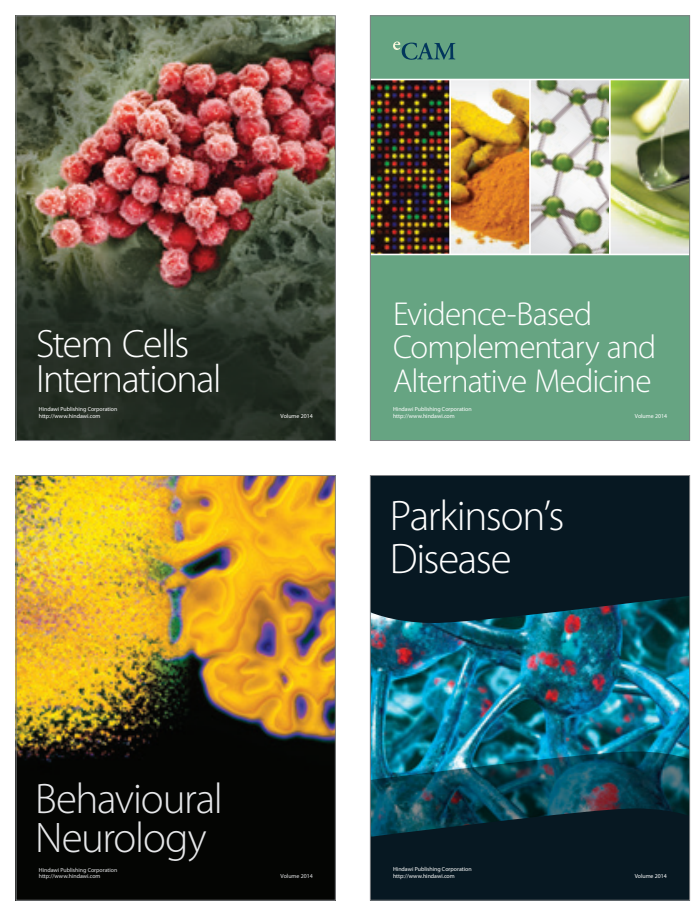

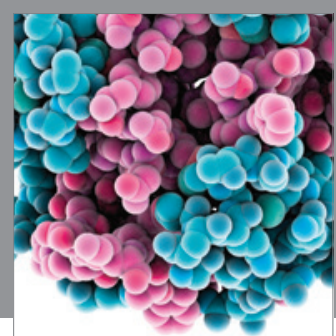

Journal of
Diabetes Research

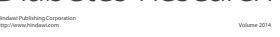

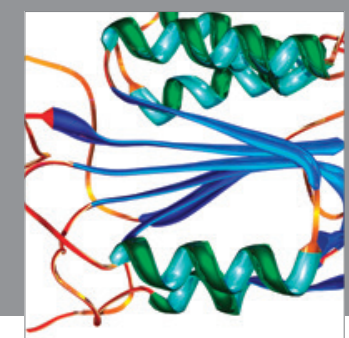

Disease Markers
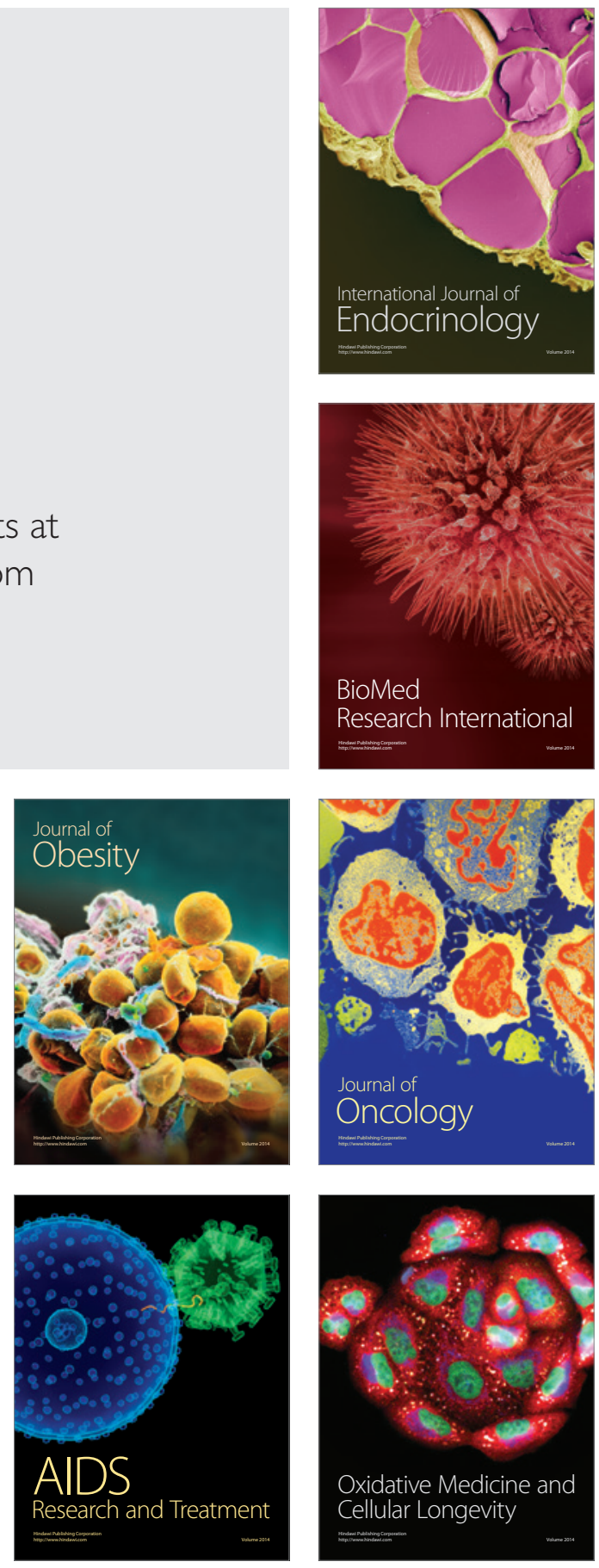